\title{
Influence of framework and interlayer on the colloidal stability of design swelling high-charged micas.
}

Francisco J. Osuna ${ }^{a}$, Agustín Cota ${ }^{b}$, Mariela. A. Fernández ${ }^{c}$, Esperanza Pavón ${ }^{a}$, Rosa M. Torres Sánchez ${ }^{c}$, María D. Alba ${ }^{a *}$

${ }^{a}$ Instituto Ciencia de los Materiales de Sevilla, ICMS, (CSIC-US). Avda. Americo Vespucio, 49. 41092 Sevilla, Spain

${ }^{b}$ Laboratorio de Rayos X, LRX-CITIUS, (US). Avdda. Reina Mercedes, 4. 41012 Sevilla, Spain

${ }^{c}$ Centro de Tecnología de Recursos Minerales y Cerámica (CETMIC-CONICET CCT-La Plata) Camino Centenario y 506, M.B. Gonnet, Argentina.

\begin{abstract}
Stability of colloidal clay minerals dispersion of fundamental in many industrial processes. Therefore, surface charge of the synthetic swelling high-charged mica family, Na-Mica-n ( $\mathrm{n}=2$ or $4, \mathrm{n}$ is the total layer charge) were investigated to study its colloidal dispersion stability as a function of the framework and interlayer space composition. NaMica-n ( $\mathrm{n}=2$ or 4 ) micas were synthesized and functionalized with ethylammonium, mercaptoethylammonium or octadecylammonium. Their zeta-potential evolutions as a function of solution $\mathrm{pH}$ were correlated with their structural, compositional and morphological characteristics. The results have shown that the total charge of swelling high charged micas, Mica-n, didn't affect significantly their colloidal dispersion stability, the interlayer composition and interlayer cation arrangement were the main factors of colloidal behaviour. The synthesis and functionalization of those synthetic micas can be tuned for their optimal use.
\end{abstract}

Keywords. Colloidal stability; design micas; surface charge; zeta potential

\footnotetext{
*Corresponding author. E-mail address: alba@icmse.csic.es
} 


\section{Introduction}

Although swelling 2:1 phyllosilicates have traditionally been considered to be those containing a total layer charge between 0.4 and 1.8 per unit cell (smectite and vermiculite groups), a new family of synthetic swelling micas, Na-Mica-n: $\mathrm{Na}_{\mathrm{n}}\left(\mathrm{Si}_{8-}\right.$ $\left.{ }_{n} \mathrm{Al}_{n}\right)\left(\mathrm{Mg}_{6}\right) \mathrm{O}_{20} \mathrm{~F}_{4}$, with tuned layer charge (n) values between 2.0 and 4.0 per unit cell has recently been synthesized [1-3] and a general synthetic method has been reported [4]. These swelling high charged micas, in which the layer charge can be adjusted, could be highly valuable for the decontamination of harmful metal cations via ion-exchange reactions [5] and for the selective removal of highly radioactive ions $[6,7]$ and hydrocarbon molecules $[8,9]$. In fact, those synthetic micas overcome some limitations of the natural clay minerals to be used as host materials.

Organoclays (OC) denotes a family of hydrophobic materials, obtained by modifying clay minerals with various organic compounds through intercalation processes and surface grafting [10-12]. Organoclays have important applications as adsorbents of organic pollutants [13] and as components for the formation of clay polymer nanocomposites [10,14]. In concrete, the organo-functionalized synthetic swelling micas with long chain alkylammonium cations have shown a good adsorption capacity of nonionic hydrocarbons [9].

Stability on solution of clay minerals and the transition between stable colloidal dispersions and coagulated or flocculated systems are decisive processes for their applications in several industrial processes as well as in soil chemistry and environmental science. If they show stability in suspension, they could be used in barrage and water lines construction, detergent soap or medicine. However, if they show tendency to flocculation, they could be used in casting field and concrete production [15]. 
The electric potential at the shear plane between a particle and the surrounding liquid when the charge particle moves in an electric field is one of the most important surface properties of minerals that determine their effectiveness for commercial use. Some properties such as rheological properties of clay-water suspension are complex, and nor full understood. This complexity arises from the sign and magnitude of surface potential of the crystal face where an electric double layer is developed. Zeta potential is a measure of the surface charge of clay particles and hence it is closely related to the atomic properties such as atomic radius and atomic charge of exchangeable cations.

In spite of the applicability of Na-Mica- $n$ on environmental decontamination [59], up to our knowledge, their colloidal stability has not been explored yet. Thus, the goal of this research was to determine the colloidal stability of the Na-Mica-n and to modify it as a function of their tuneable structural and compositional parameters such as total layer charge or interlayer space composition. Taken into account that the interlayer space of swelling 2:1 phyllosilicates plays an important role in geochemical, environmental, and industrial processes $[16,17]$, it is important to explore in deep how the nature of interlayer cations and the hydrophobicity of Na-Mica-n surface controls their colloidal stability.

\section{Materials and methods}

\subsection{Materials}

Two swelling high charged micas, Na-Mica-n ( $\mathrm{n}=2$ or $4, \mathrm{n}$ is the layer charge) $\mathrm{Na}_{n}\left[\mathrm{Si}_{8-\mathrm{n}} \mathrm{Al}_{n}\right] \mathrm{Mg}_{6} \mathrm{O}_{20} \mathrm{~F}_{4}$, was synthesized as previously described by Alba et al. [4].

The chemical products used for the preparation of the organoclays were obtained from Aldrich Chemical Co. Octadecylamine was firstly converted to the protonated form by adding $0.1 \mathrm{M} \mathrm{HCl}$ aqueous solution in a molar ratio amine: $\mathrm{HCl} 1: 1$ and stirred at 80 
${ }^{\circ} \mathrm{C}$ for $3 \mathrm{~h}$. Then, $600 \mathrm{mg}$ of mica were added to the protonated amines, octadecylammonium (ODA: $\mathrm{C}_{18} \mathrm{H}_{37} \mathrm{NH}_{3}{ }^{+}$), ethylammonium (EA: $\mathrm{C}_{2} \mathrm{H}_{5} \mathrm{NH}_{3}{ }^{+}$) and mercaptoethylammonium (MEA: $\mathrm{SHC}_{2} \mathrm{H}_{4} \mathrm{NH}_{3}{ }^{+}$), in excess, higher than 1.5 time their cation exchange capacity, in order to favour the cation exchange reaction and left to react for $3 \mathrm{~h}$ at $80^{\circ} \mathrm{C}$. The organoclays were recovered by centrifugation, washed with deionized water and ethanol and dried at room temperature. The amount of adsorbed ammonium is shown in Table 1.

The set of analysed samples, summarized on Table S1, allowed us to shed a light on the influence of both framework and interlayer space on their colloidal behaviour. Moreover, ODA-M4 was prepared at three different $\mathrm{OAD}^{+}$load to evaluate the influence of the ammonium concentration.

\subsection{Measurements}

X-ray diffraction (XRD) pattern were obtained at the X-ray laboratory (CITIUS, University of Seville, Spain) on a Bruker D8 Advance instrument equipped with a $\mathrm{Cu} \mathrm{K}_{\alpha}$ radiation source operating at $40 \mathrm{kV}$ and $40 \mathrm{~mA}$. Diffractograms were obtained in the $2 \theta$ range of $1.5-70^{\circ}$ with a step size of $0.015^{\circ}$ and a step time of $0.1 \mathrm{~s}$.

Thermogravimetric analysis, TG, were carried out using a TA (model STD-Q600) instrument, in Characterization Service (CITIUS, University of Seville, Spain), with alumina as reference. The samples were placed into a Pt crucible and maintained at air throughout the heating period. The temperature was increased at a constant rate of $10^{\circ}$ $\mathrm{C} / \mathrm{min}$. The temperature of each loss weight on the TG was determined thorough the derivative TG curve as a function of temperature (DTG).

The total specific surface area (TSSA) were determined from the adsorption of water vapour at a relative humidity of 0.56 , as described elsewhere [18]. 
The particle size distribution of water suspension was measured using a laser diffraction particle size analyser (Mastersize 2000 Model Hydro2000SM, Malvern Instrument Ltd., UK). The size-frequency distributions were plotted and cumulated particle size at $50 \%$ distribution $\left(\mathrm{D}_{50 \%}\right)$ and polydispersity index $(\mathrm{PI})$ were determined.

Electrokinetic potentials were determined in a Brookhaven 90Plus. The electrophoretic mobility was converted into zeta potential values using the Smoluchowski equation. For each determination, $40 \mathrm{mg}$ of sample were dispersed in $40 \mathrm{~mL}$ of a $10^{-3} \mathrm{M}$ $\mathrm{KCl}$ solution, the slurry was stirred and $\mathrm{pH}$ was measured and it value has been named as natural $\mathrm{pH}$. To generate zeta potential versus $\mathrm{pH}$ curves, the $\mathrm{pH}$ of the slurry was adjusted using dilute $\mathrm{HCl}$ and $\mathrm{KOH}$ solutions followed by magnetic stirring until equilibrium was attained. In general, the covered $\mathrm{pH}$ range was between 2.5 and 11.0. The MEA-M2 precipitated at $\mathrm{pH} \leq 4.0$ and, thus, the covered $\mathrm{pH}$ range for this sample was between 4.0 and 11.0.

\section{Results and discussion}

\subsection{Effect of the framework composition: Layer charge}

In the DTG curves, Fig. S1, two regions were clearly differentiated and the amount of interlayer water was determined from the weight loss in the temperature range of $25-150{ }^{\circ} \mathrm{C}$ and the amount of the adsorbed alkylammonium cations was determined from the weight loss between $150^{\circ} \mathrm{C}$ and $900{ }^{\circ} \mathrm{C}$ [19]. Table 1 showed the loss weight of both regions, the total adsorbed water, the coordination number of the coordination sphere of each cations and the percentage of cation exchanged capacity satisfied by the alkylammonium cation.

The number of water molecules per unit cell of Na-Mica-n was slightly lower than that observed for smectite or vermiculite (ca. 4) [20]. The extremely low values of the 
water molecules per cation were due to an interaction between the interlayer $\mathrm{Na}^{+}$and the negative electrostatic force of the layers and this effect was higher as the layer charge increased [21]. The small weight loss in the region of 150 and $900{ }^{\circ} \mathrm{C}$ corresponded to dehydroxylation of the aluminosilicate framework [19] even when the mica was fluorinated, a small amount of $\mathrm{F}^{-}$was substituted by $\mathrm{OH}^{-}$.

In the case of ODA-Mica-n, Fig. S1, three weight loss steps were observed in the temperature range $150-900{ }^{\circ} \mathrm{C}$. The first step, $150-300{ }^{\circ} \mathrm{C}$, corresponded to the evaporation of weakly adsorbed organic molecules [22], the second step, $300-400{ }^{\circ} \mathrm{C}$, was associated to the thermal degradation of intercalated alkylammonium ions [23], and, finally, the mass loss beyond $400{ }^{\circ} \mathrm{C}$ resulted from the decomposition of the residual carbonaceous intermediates $[22,24]$. The weight loss in second region revealed that the CEC was completely satisfied and a limited additional adsorption, an excess of ca. $50 \%$, occurred beyond the CEC. The additional alkylammonium cations exceeding the mica exchange capacity were likely to be adsorbed between the silicate layers due to van der Waals interactions between alkyl chains [25]. The number of water molecules per cation remained constant in ODA-M4-B and decreased dramatically in ODA-M2.

Fig. 1a and Fig. 2a showed the XRD patterns obtained for the Na-M4 and Na-M2, respectively, a unique do01 reflection was observed at $7.25^{\circ}-7.35^{\circ} 2 \theta$, corresponding to a spacing value of 1.22-1.18 nm due to a water pseudomonolayer [26], in good agree with the low water content measured by TG (Table 1).

The exchanged of interlayer $\mathrm{Na}^{+}$by $\mathrm{ODA}^{+}$provoked a shift of the 001 reflection to lower 2 $\theta$, higher interlayer space, (Fig. 1e and Fig. 2d) in both micas, moreover, up to four 001 refection were observed. Whereas, two 001 reflection sequences were observed in ODA-M2, a unique 001 reflection family was observed in ODA-M4-B because the double interlayer charge provoked that the interlayer cation density increased and the 
freedom degree of ODA cations decreased [27]. Ganguly et al. [28] observed the same heterogeneity in the interlayer arrangement of organic cations in the interlayer space of montmorillonites and concluded that both the cation exchange capacity and the layer charges of the silicates played a dominant role in the interlayer arrangements of the organic cations.

The do01 basal spaces were much greater than basal space of low charge 2:1 phyllosilicates to allow the surfactant to be accommodated in a close and ordered package. Alkylammonium ions in the interlayer space of 2:1 phyllosilicates can acquire distinct arrangements and provide different basal space (d001) as represented in Fig. S2 $[29,30]$. The transition between one-layer/two-layer and two-layer/three-layer occur if the area per alkylammonium ion $\left(\mathrm{A}_{\mathrm{c}}=0.0572 \cdot \mathrm{n}_{\mathrm{c}}+0.14\left(\mathrm{~nm}^{2}\right)\right)[31]$ is equal or twice the equivalent area $\left(A_{e}=[a \cdot b] / \xi\right)$, where $n_{c}=$ length of alkyl chain; $\xi=$ interlayer cation density (average layer charge in eq/(Si,Al) $\left.)_{4} \mathrm{O}_{10}\right)$ and $\mathrm{a}$ and $\mathrm{b}$ are lattice parameters $(0.534$ and $0.925 \mathrm{~nm}$ for the micas) [32]. In the case of ODA-M4-B and ODA-M2, the Ac/Ae ratios (Table 1) were compatible with a paraffin structure with a tilt angle $(\alpha)$ with the solid surface calculated from the experimental basal space: $\mathrm{d}_{001}=\mathrm{p} \cdot\left[\left(\mathrm{n}_{\mathrm{c}}-1\right) \cdot 0.126+\right.$ $0.131] \cdot \sin \alpha+0.94(\mathrm{~nm})$ for paraffinic structure [33], where $\mathrm{p}=1$ for paraffinic monolayer and 2 for paraffinic bilayer. The experimental do01 values (Fig. 1e and Fig. 2d) corresponded to the arrangement of alkylammonium in paraffinic bilayer with tilt angle of $59.6^{\circ}$ for ODA-M4-B and $64.4^{\circ}$ and $37.5^{\circ}$ ODA-M2 [29].

The particle diameter distribution of the micas showed a monomodal character when $\mathrm{Na}^{+}$was the interlayer cation and a bimodal character for $\mathrm{ODA}^{+}$as interlayer cation (Fig. S3 and S4), because the alkylammonium could favour particle aggregations [34]. The $\mathrm{D}_{50 \%}$ and PI were shown in Table 2, and statically lower sizes and narrower distributions were observed in Mica-4 than in Mica-2 and both parameters increased by 
the exchange of $\mathrm{Na}^{+}$by $\mathrm{ODA}^{+}$. The total surface area, TSSA, showed the same trends than particle size (Table 2). In general, the low TSSA value of the Na-Mica-n in comparison with those showed by Na-montmorillonite [35] would be explained by the low interlayer water uptake (see Table 1) which increased the electrostatic interaction between interlayer $\mathrm{Na}^{+}$and mica framework and inhibited further swelling [36, 37]. Those electrostatic interaction increases with the total layers and lower TSSA values were observed in Na-M4 than in Na-M2. The exchanged of $\mathrm{Na}^{+}$by $\mathrm{ODA}^{+}$diminished drastically the TSSA values (TSSA decreased in a ca. 90\%) because a smaller amount of water was taken up (Table 1) and the surface area measured by water adsorption being reduced [38], similar behaviour was observed in montmorillonite and kaolinite saturated with alkylammonium cations [39]. Bridley [40] observed that a tilt angle of $50^{\circ}-51^{\circ}$ allowed the optimal interaction of the $\mathrm{NH}_{3}{ }^{+}$group with the basal oxygens of the tetrahedral sheet of clay minerals and the increasing of this angle in highly charged micas (Fig. 1 and Fig. 2) was possible by the incorporation of the $\mathrm{NH}_{3}{ }^{+}$group into the pseudohexagonal hole (inner-sphere interaction) [8]. On one hand, the migration of interlayer cations into the pseudohexagonal hole caused a layer charge reduction [41] and consequently the surface area hydration capacity [42], the TSSA of ODA-Mica-n being decreased up to ca. $90 \%$. On the other hand, Pavon et al. [21] observed that the capacity of partial interaction of interlayer cations with the basal oxygens of tetrahedral sheet of Mica-4 was higher than in Mica-2, and thus, being the responsible of the higher TSSA diminishing of ODA-M4-B (ca. $95 \%$ ) vs ODA-M2 (ca. $88 \%$ ).

2:1 phyllosilicates have two types of electrical charge, one is the constant negative face charge, due to isomorphic substitution [43], and the other is the $\mathrm{pH}$ dependent edge charge [38]. For many low charged 2:1 phyllosilicates (such as smectites and vermiculites) the edge charge comprises only about $20 \%$ of the total charges [23] and 
zeta potential values (ca. $-20 \mathrm{mV}$ ) exhibit flat curves without significant changes over a wide range of $\mathrm{pH}$ values [35, 44-47]. However, swelling high-charged micas, Na-Mica$\mathrm{n}$, showed a zeta potential that changed significantly in the $\mathrm{pH}$ range. At acid $\mathrm{pH}$, the zeta potential (Fig. 3) was positive due to edge charge created by the presence of heterogeneous $-\mathrm{SiOH}$ and $-\mathrm{AlOH}$ sites [48], and at $\mathrm{pH}>3.5$, the zeta potential was negative with an almost constant negative value (ca.- $25 \mathrm{mV}$, typical of permanent charge of $2: 1$ phyllosilicate [35]) in the $\mathrm{pH}$ range 5-9. At $\mathrm{pH}>9$, the zeta potential become more negative, being more negative for Na-M4 than for Na-M2. The lowering of zeta potential (more negative) at basic range could be due to the hydroxyl groups of the broken octahedral sheet [48].

In both micas, the $\mathrm{pH}$ of the point of zero charge (pzc) was below 3.5 (Fig. 4) which is quite acid in comparison with the value for montmorillonites, with permanent charge, $(\mathrm{pH}$ ca. 5) $[49,50]$ or pyrophyllite, without permanent charge, $(\mathrm{pH}=4.2)[51]$ and could be due to the high permanent charge of mica which enhanced the acidity of the surface [52], and, thus a lowering of the pzc pH. The $\mathrm{pH}$ of pzc of Na-M4 was higher than Na-M2 in spite of it higher charge. On one hand, the interlayer $\mathrm{Na}^{+}$are partially coordinated by the basal oxygens of the Na-M4 tetrahedral sheet [21] which caused a layer charge reduction [41] and an increase of the pzc pH. On the other hand, the particle size of Na-M4 was smaller than Na-M2 particle size (Table 2) and the contribution of the edge charge become significant as particle size decreases [53] and it contributed to the increase of the $\mathrm{pH}$ of $\mathrm{pzc}$ [54].

The adsorption of $\mathrm{ODA}^{+}$provoked a drastically change in the zeta potential plots (Fig. 3) and pzc pH shifted to basic range (Fig. 4). The reverse of the charge surface was due to the screening of the initial surface charge [55] that was covered by a ODA ${ }^{+}$bilayer arrangement with some positive ammonium groups oriented out the surface $[56,57]$. The 
layer charge influence on the zeta potential was similar than those observed by Na-Mican. At $\mathrm{pH}>9$, there was not difference between Na-Mica-n and ODA-Mica-n because at basic range the zeta potential was dominated by the edge charge due to octahedral sheet defects.

Fig. 4 showed that, at natural $\mathrm{pH}$, Na-Mica-n dispersions were more stables than the ODA-Mica-n because of their hydrophilic character, and this stability increased with the increasing of the total charge.

\subsection{Effect of the interlayer space composition}

\subsubsection{Hydrophobicity of the interlayer space.}

Three ODA-Mica-4 were prepared at different $\mathrm{ODA}^{+}$concentration and the weight loss in the range $150-900{ }^{\circ} \mathrm{C}$ (Table 1) has showed that whereas $\mathrm{ODA}^{+}$load was not enough to satisfy completely the CEC of ODA-M4-A, in the other two samples an excess of ca. $60 \%$ and $80 \% \mathrm{ODA}^{+}$was adsorbed beyond the CEC. An increasing of the intensity of the DTG peak at ca. $250{ }^{\circ} \mathrm{C}$ vs the peak at ca. $305^{\circ} \mathrm{C}$ (Fig. S1) was observed when the excess of $\mathrm{ODA}^{+}$increased. The number of water molecules per cation drastically decreased in ODA-M4-A as consequence of the interlayer exchanged of hydrophilic $\mathrm{Na}^{+}$ by the hydrophobic $\mathrm{ODA}^{+}$. However, the water amount increased when $\mathrm{ODA}^{+}$was adsorbed in excess and it could be due to hydration of polar head of $\mathrm{ODA}^{+}$adsorbed as ionic par.

The exchange reaction between $\mathrm{Na}^{+}$and the $\mathrm{ODA}^{+}$in Mica- 4 caused an increase in the basal spacing ( $\left.\mathrm{d}_{001}\right)$, compatible with paraffinic bilayer-type structures [30], and an unique and well-ordered sequence of the 001 reflections was observed for all the samples,

Fig. 1d-1f. As the alkylammonium load increased, the 001 reflection shifted to higher $2 \theta$, 
lower basal space, and the tilt angle of alkylammonium paraffin bilayer decreased from ca. $61^{\circ}$ to $57^{\circ}$.

As described in the previous section the exchanged of $\mathrm{Na}^{+}$by $\mathrm{ODA}^{+}$provoked a bimodal particle distribution and the second peak shifted at higher particle size when alkylammonium was adsorbed more than 1.5 CEC, ODA-M4-C (Fig. S3). In general, $\mathrm{D}_{50 \%}$ increased (Table 2) as consequence of exchanged of $\mathrm{Na}^{+}$for $\mathrm{ODA}^{+}$and the increment was higher when the adsorption was higher than 1 CEC (ODA-M4-A), being constant after excess of adsorbed ODA (ODA-M4-B and ODA-M4-C). A slight decrease of TSSA values was observed when alkylammonium concentration increases (Table 2) which was caused by the hydrophobic environment of ODA-Mica-4, as previously reported for montmorillonite [18].

The data of the zeta potential vs pH (Fig. 5) indicated that the specific charge of swelling high charged mica shifted from negative to positive values at natural $\mathrm{pH}$ (Fig. 4) as consequence of the $\mathrm{ODA}^{+}$uptake even when $\mathrm{ODA}^{+}$loading was below CEC (ODAM4-A), as previously reported for bentonite [58]. Churchman [59] observed that quaternary ammonium derivatives of polymers were adsorbed simultaneously in the interlayer space of montmorillonite and in the external surface even at very low loadings (i.e. $0.5 \mathrm{CEC})$.

No significant effect on zeta potential was observed as function of $\mathrm{ODA}^{+}$ loading, as previously reported by Zadaka et al. [60], and was interpreted as micelle formation and affinity of the cations for the clay surface. Table 2 and Fig. S3 evidenced the aggregation of particles in presence of $\mathrm{ODA}^{+}$, compatible with the bimodal particle size distribution and the increase of the $\mathrm{D}_{50 \%}$ value of $13.5 \%$ when $\mathrm{ODA}^{+}$was loaded below CEC (ODA-M4-A) and $19 \%$ for ODA ${ }^{+}$load in excess of CEC (ODA-M4-B and ODA-M4-C). 


\subsubsection{Length of the alkyl chain.}

The effect of the alkyl chain length was analysed thorough the comparison of EA-M4 and ODA-M4-A, in which the adsorbed alkylammonium cations were not enough to satisfy completely the CEC of mica (Table 1). In both cases, the water content decreased with respect to the raw Na-M4 but it was more drastic in the case of ODA-M4-A than in EA-M4 because the hydrophobicity of alkylammonium increased as alkyl chain length increased [8].

The length of the alkyl chain affected also the interlayer arrangement of the molecules since the ODA-M4-A Ac/Ae ratio (Table 1) was compatible with a paraffin structure [61] but the EA-M4 $\mathrm{A}_{\mathrm{c}} / \mathrm{A}_{\mathrm{e}}$ ratio (Table 1) favoured a lateral bilayer conformation [61]. Thus, the do01 space $(1.60 \mathrm{~nm})$ of EA-M4 (Fig. 1b) was much lower than that (4.92 nm) of ODA-M4-A (Fig. 1d). A unique 001 reflection family was also observed in EA$\mathrm{M} 4$, since the $\mathrm{A}_{\mathrm{c}} / \mathrm{A}_{\mathrm{e}}$ ratio equals to one demanded a well order closed-packed configuration.

As the alkyl chain length increased (EA-M4 vs ODA-M4-A), the D50\% and PI increased (Table 2) due to the higher tendency to micellar aggregation [34]. The adsorption of $\mathrm{EA}^{+}$, as $\mathrm{ODA}^{+}$, decreased the TSSA up to a $55 \%$ since a smaller amount of water was taken up (Table 1) and then, the surface area measured by water adsorption was reduced [38]. However, the TSSA drop of EA-M4 was lower than ODA-M4-A, and it could not be only due to a drastically decrease of water uptake but also due to the configuration of the both alkylammonium in the interlayer space as observed by XRD (Fig. $1 \mathrm{~b}$ and 1e). The lateral bilayer configuration of $\mathrm{EA}^{+}$did not favour the incorporation of the $\mathrm{NH}_{3}{ }^{+}$group into the pseudohexagonal hole that was the main factor for the drastically decrease of the TSSA of ODA-M4-A. 
A drastically change in the zeta potential evolution with $\mathrm{pH}$ was observed as a function of the alkyl chain length (Fig. 5, EA-M4 and ODA-M4-A). The loading of alkylamonium of short alkyl chain length $\left(\mathrm{EA}^{+}\right)$did not shift the specific charge from negative to positive values at natural $\mathrm{pH}$ (Fig. 4) as occurred with long chain alkylammonium $\left(\mathrm{ODA}^{+}\right)$due to the smaller hydrophobicity of $\mathrm{EA}^{+}$(Table 1). The evolution of zeta potential of EA-M4 was quite similar to Na-M4 but EA ${ }^{+}$provoked a shift of the pzc $\mathrm{pH}$ at lower $\mathrm{pH}$. The lowering of the $\mathrm{pzc} \mathrm{pH}$ could be due to the lateral bilayer configuration of the interlayer $\mathrm{EA}^{+}$, as observed by XRD, which did not allowed the incorporation of $\mathrm{NH}_{3}{ }^{+}$in the pseudohexagonal hole and, thus, the layer charge was not reduced as in $\mathrm{Na}-\mathrm{M} 4$, with $\mathrm{Na}^{+}$forming a partial inner sphere complex [41]. At natural $\mathrm{pH}$, the $\mathrm{EA}^{+}$loading stabilized the Mica-4 dispersion (Fig. 4).

\subsubsection{Nature of the functional group of the alkyl chain.}

The effect of the nature of functional group of the alkyl chain was analysed thorough the comparison of EA-Mica-n and MEA-Mica-n, in which the adsorbed alkylammonium cations (Table 1) were not enough to satisfy completely the CEC of mica in the case of Mica-4 (75.5\% for EA-M4 and 66.5\% for MEA-M4) and CEC was satisfied in Mica-2 (96.5\% for EA-M2 and $105.0 \%$ for MEA-M2). In both cases, the water content decreased with respect to the original Na-Mica-n, and the water content was directly related to the $\%$ CEC satisfied.

The total layer of the mica determined the optimum interlayer arrangement of $\mathrm{EA}^{+}$ and $\mathrm{MEA}^{+}$. Whereas, the $\mathrm{A}_{\mathrm{c}} / \mathrm{A}_{\mathrm{e}}=1$ for $\mathrm{X}-\mathrm{M} 4(\mathrm{X}=\mathrm{EA}$ or MEA) favoured lateral bilayer conformation, the $\mathrm{A}_{\mathrm{c}} / \mathrm{A}_{\mathrm{e}}=0.5$ for $\mathrm{X}-\mathrm{M} 2(\mathrm{X}=\mathrm{EA}$ or $\mathrm{MEA})$ favoured lateral monolayer conformation [61].

The XRD patterns of X-M4 (X=EA or MEA) (Fig. 1b and 1c) showed a basal space of ca. $1.60 \mathrm{~nm}$, typical of lateral bilayer, as predicted by the geometrical 
considerations (Fig. S2). Additionally, MEA-M4 showed a second very small 001 reflection at $1.37 \mathrm{~nm}$ due to monolayer conformation (Fig. S2). The XRD patterns of XM2 (X=EA or MEA) (Fig. 2b and 2c) showed at least two set of 001 reflections due to simultaneous formation of lateral monolayer and lateral bilayer conformations, even when the $A_{c} / A_{e}$ ratio was lower than the monolayer/bilayer transition [61].

The effect of the thiol functional group on textural properties (EA-Mica-n vs MEA-Mica-n) was inverse when Mica-4 and Mica-2 were compared (Table 2). In the case of Mica-4, ca.0.7 CEC was satisfied, the particle size increased and TSSA decreased as consequence of thiol group but in Mica-2, ca. 1 CEC was satisfied, the particle size was not affected and the TSSA increased.

Fig. 6 showed the effect of thiol functional group (MEA-Mica-n) on the zeta potential in a wide range of $\mathrm{pH}$. The evolution of the zeta potential of MEA-Mica-n with $\mathrm{pH}$ was quite similar to those of EA-Mica-n, and indicated that the length and configuration of the alkyl chain was the main factor of the qualitative evolution of the charge with $\mathrm{pH}$. However, the plot of MEA-Mica-n shifted at a less negative value in the acid range due to the thiol group was easily protonated at this range $\left(-\mathrm{SH}_{2}{ }^{+}\right.$being generated), the permanent negative charge of mica being partially neutralized, and thus, the pzc was shifted to higher $\mathrm{pH}$ value and the mica dispersion was stabilized at natural pH (Fig.4).

\section{Conclusions}

For the first time, the colloidal dispersion stability of the design swelling high charged micas has been proved. The total charge of swelling high charged micas, Mican, didn't affect significantly the colloidal dispersion stability, the interlayer composition and interlayer cation arrangement were the main factors of the colloidal behaviour. 
The long chain alkylammonium cations were able to shift the superficial charge of micas and thiol functional groups in the alkyl chain providing an extra stabilization of colloids at natural $\mathrm{pH}$.

Finally, the stability $\mathrm{pH}$ range of the Mica-n colloids was established as a function of the total layer charge and the composition of the interlayer space. Within this scenario, the design of the mica synthesis and functionalization would allow tuning their optimal applications.

\section{Acknowledgements}

The authors would like to thank the Junta de Andalucía (Spain) and FEDER (Proyecto de Excelencia de la Junta de Andalucía, project P12-FQM-567), to the Spanish State Program $\mathrm{R}+\mathrm{D}+\mathrm{I}$ oriented societal challenges and FEDER (Project MAT201563929-R) for financial support. F.J. Osuna thanks his grant to the training researcher program associated to the excellence project of Junta de Andalucía (P12-FQM-567) and to University of Seville-Banco Santander for the mobility grant.

\section{Appendix A. Supplementary data}

Supplementary data associated with this article can be found, in the online version. 
Table 1.

Weight loss, proportion of organic cation adsorbed as function of the CEC (\% $\mathrm{CEC})$, water content and ratio of alkylammonium area and equivalent area $\left(A_{c} / A_{e}\right)$.

\begin{tabular}{llllllll}
\hline & \multicolumn{3}{l}{$\%$ weight loss } & & \multicolumn{2}{l}{$\mathrm{mol} \mathrm{H}_{2} \mathrm{O}$} & \\
\cline { 2 - 3 } sample & $25^{\circ}-$ & $150^{\circ}-$ & $\%$ & per mol & per mol & \\
& $150^{\circ} \mathrm{C}$ & $900^{\circ} \mathrm{C}$ & $\mathrm{CEC}^{\mathrm{a}}$ & & mica & cation & $\mathrm{A}_{\mathrm{c}} / \mathrm{A}_{\mathrm{e}}$ \\
\hline Na-M4 & 6.3 & 2.2 & 0.0 & 3.0 & 0.8 & -- \\
EA-M4 & 4.6 & 16.5 & 74.5 & 2.3 & 0.6 & 1.0 \\
MEA-M4 & 3.3 & 22.4 & 66.5 & 1.8 & 0.5 & 1.0 \\
ODA-M4-A & 1.0 & 54.1 & 88.7 & 0.9 & 0.2 & 4.7 \\
ODA-M4-B & 2.4 & 71.0 & 159.9 & 3.2 & 0.8 & 4.7 \\
ODA-M4-C & 1.5 & 74.1 & 177.4 & 2.2 & 0.6 & 4.7 \\
Na-M2 & 6.8 & 2.2 & 0.0 & 3.1 & 1.5 & - \\
EA-M2 & 3.3 & 12.3 & 96.5 & 1.5 & 0.8 & 0.5 \\
MEA-M2 & 5.7 & 18.9 & 105.0 & 2.9 & 1.5 & 0.5 \\
ODA-M2 & 1.9 & 54.3 & 154.3 & 1.7 & 0.8 & 2.4 \\
\hline
\end{tabular}

a $\%$ of cation exchanged capacity satisfied by the organic cation $(\mathrm{A}=\mathrm{EA}, \mathrm{MEA}$ or ODA) calculated on the basis of the chemical $\mathrm{A}_{x} \mathrm{Na}_{\mathrm{n}-\mathrm{x}}\left[\mathrm{Si}_{8-\mathrm{n}} \mathrm{Al}_{n}\right] \mathrm{Mg}_{6} \mathrm{O}_{20} \mathrm{~F}_{4}(\mathrm{n}=2$ or 4$)$

Table 2.

Particle size and total specific surface area (TSSA).

\begin{tabular}{llll}
\hline & \multicolumn{2}{l}{ Particle size } & \\
\cline { 2 - 3 } sample & $\begin{array}{l}\mathrm{D}_{50 \%} \\
(\mu \mathrm{m})\end{array}$ & PI & $\begin{array}{l}\text { TSSA } \\
\left(\mathrm{m}^{2} / \mathrm{g}\right)\end{array}$ \\
\hline Na-M4 & 3.7 & 1.4 & 247.4 \\
EA-M4 & 3.8 & 1.2 & 109.9 \\
MEA-M4 & 4.3 & 1.2 & 61.1 \\
ODA-M4-A & 4.2 & 14.2 & 12.9 \\
ODA-M4-B & 4.4 & 9.2 & 12.7 \\
ODA-M4-C & 4.4 & 59.4 & 8.2 \\
Na-M2 & 4.9 & 1.9 & 316.4 \\
EA-M2 & 4.4 & 1.8 & 74.6 \\
MEA-M2 & 4.4 & 1.7 & 236.3 \\
ODA-M2 & 5.1 & 17.5 & 36.5 \\
\hline
\end{tabular}




\section{FIGURE CAPTION}

Fig. 1. XRD of a) Na-M4, b) EA-M4, c) MEA-M4, d) ODA-M4-A, e) ODA-M4-B, and, f) ODA-M4-C.

Fig. 2. XRD of a) Na-M2, b) EA-M2, c) MEA-M2, and, d) ODA-M2.

Fig. 3. Zeta potential curves of Na-M4 (solid blue circle), Na-M2 (solid red triangle) ODA-M4-B (open blue circle), and, ODA-M2 (open red triangle).

Fig. 4. $\mathrm{pH}$ range of stability of the clay minerals dispersion. Red points indicate the point zero charge (pzc), blue stars indicate natural $\mathrm{pH}$, dash grey arrows indicate the $\mathrm{pH}$ range of aggregation or precipitation, solid grey arrows indicate the $\mathrm{pH}$ range of moderate stability, and, solid black arrows indicate the $\mathrm{pH}$ range of good stability.

Fig. 5. Zeta potential curves of Na-M4 (solid red circle), EA-M4 (open red circle), ODAM4-A (solid blue star), ODA-M4-B (solid cyan square), and, ODA-M4-C (solid green triangle).

Fig. 6. Zeta potential curves of EA-M4 (solid blue circle), MEA-M4 (open blue circles), EA-M2 (solid red triangle), and, MEA-M2 (open red triangle). 
Fig. 1

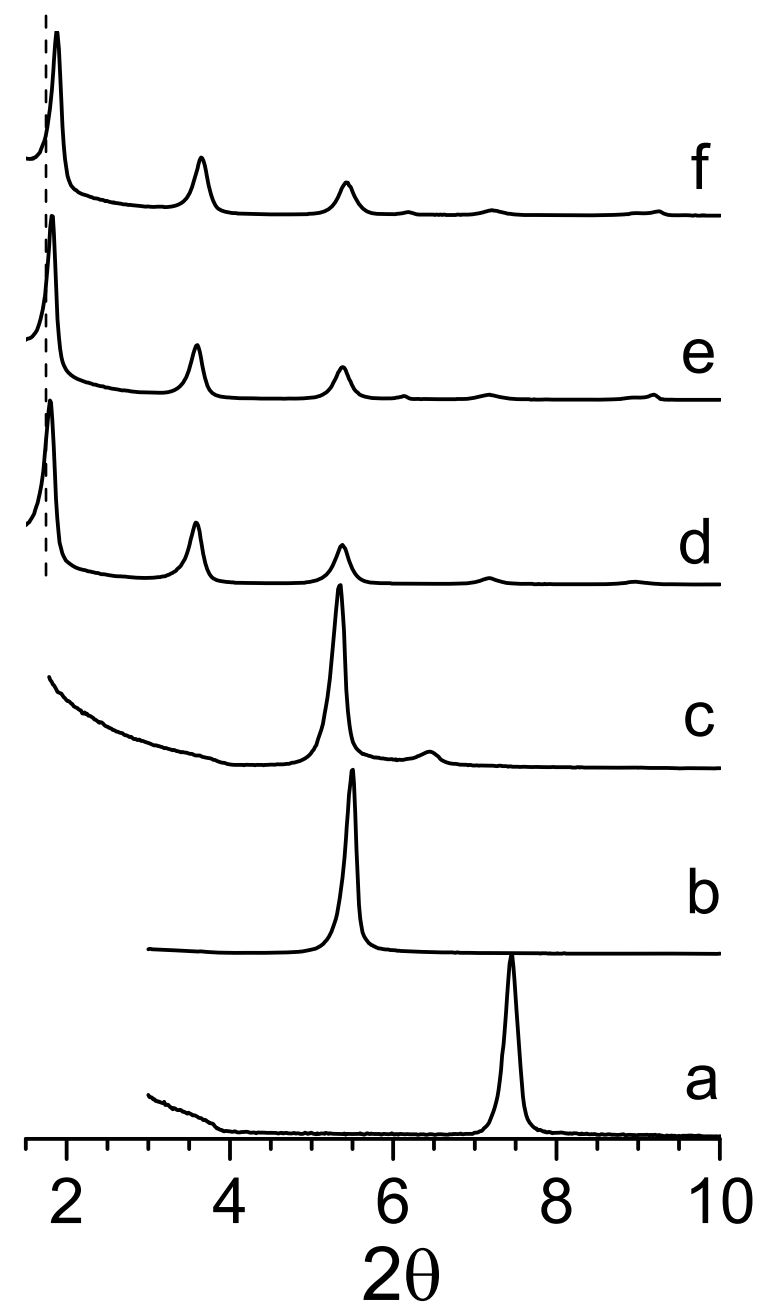


Fig. 2

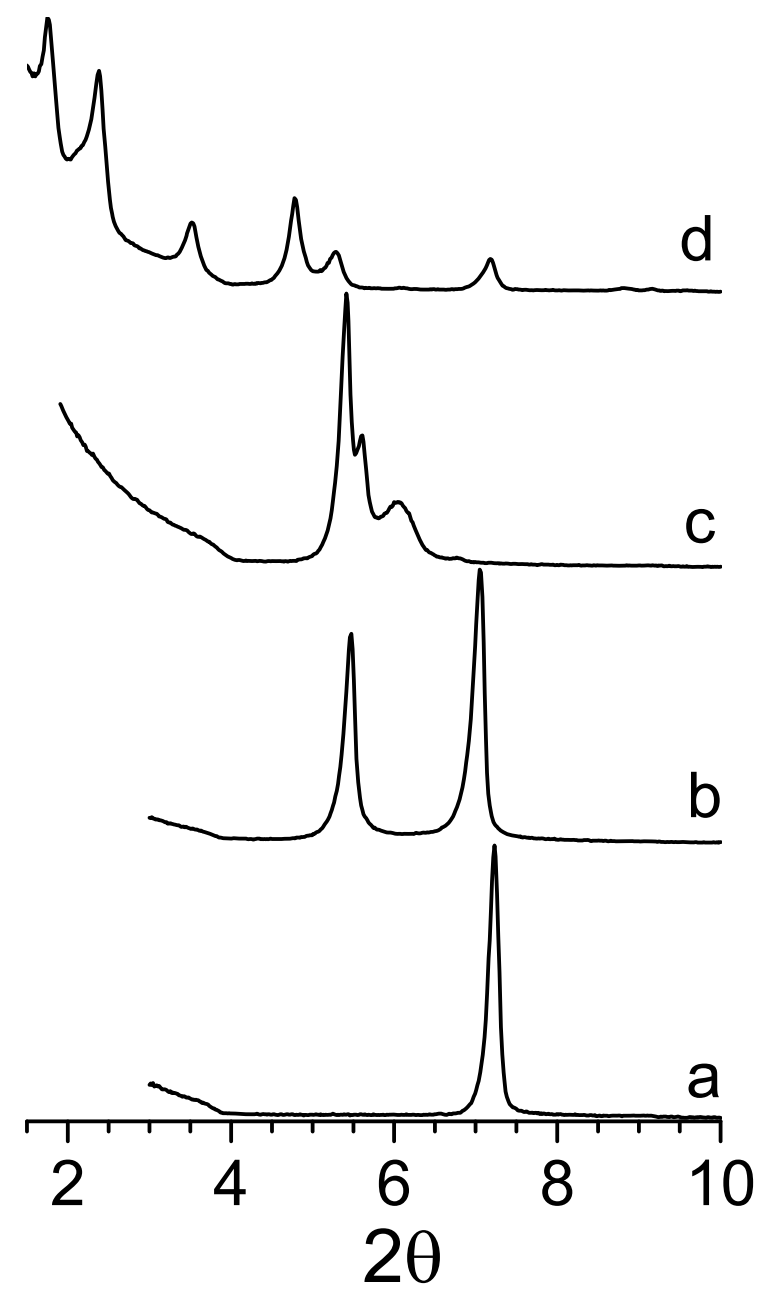


Fig. 3

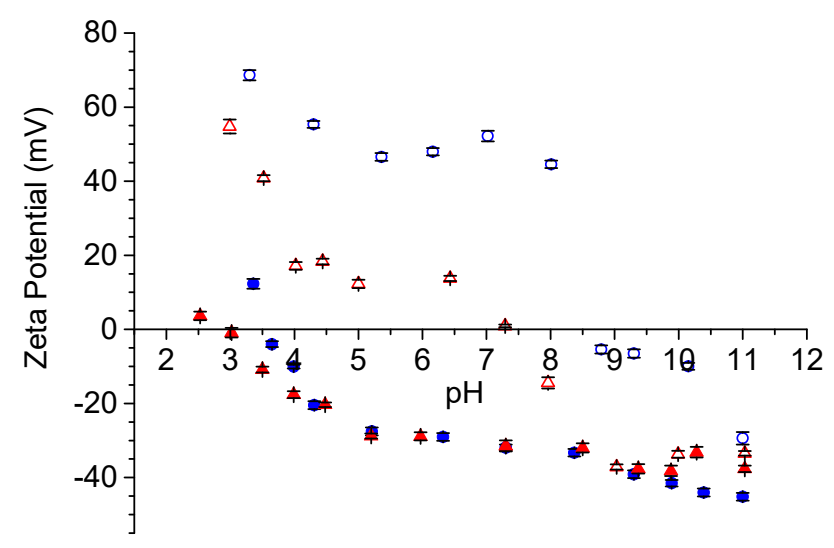


Fig. 4

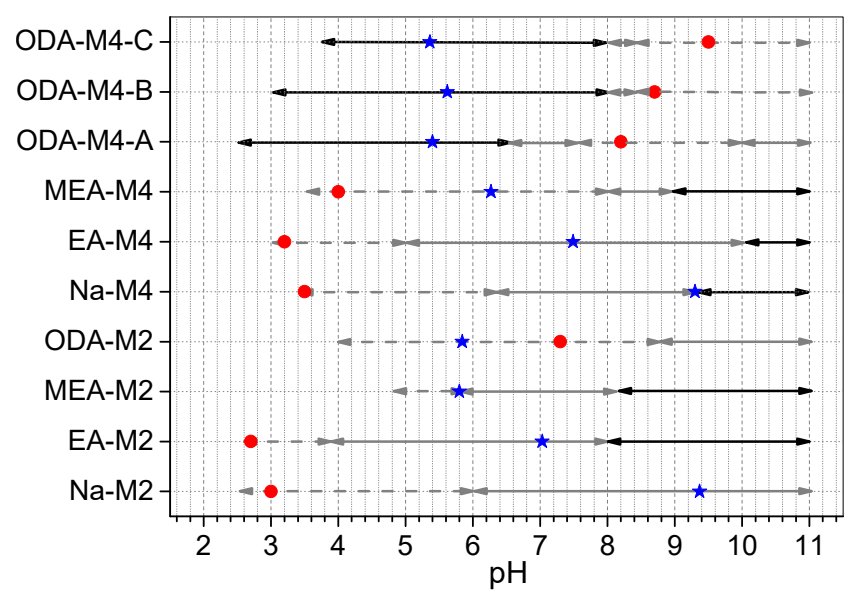


Fig. 5

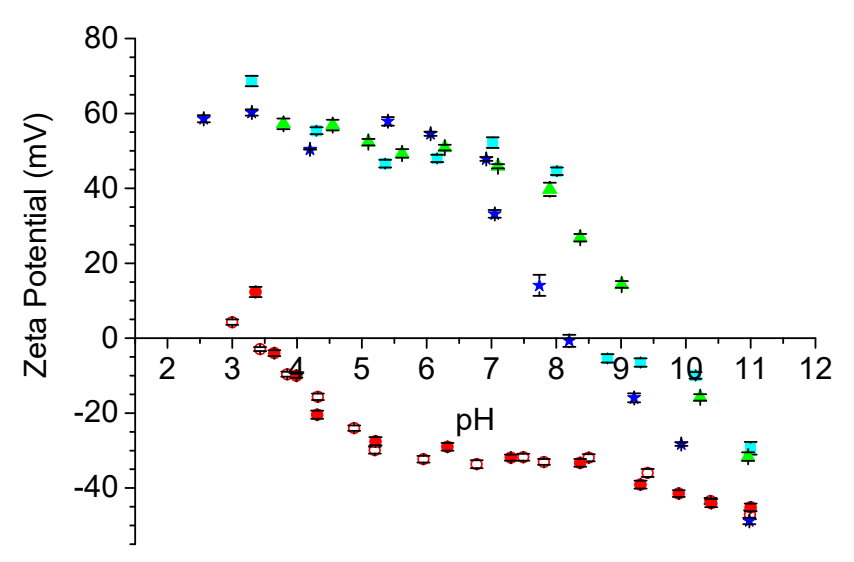


Fig. 6

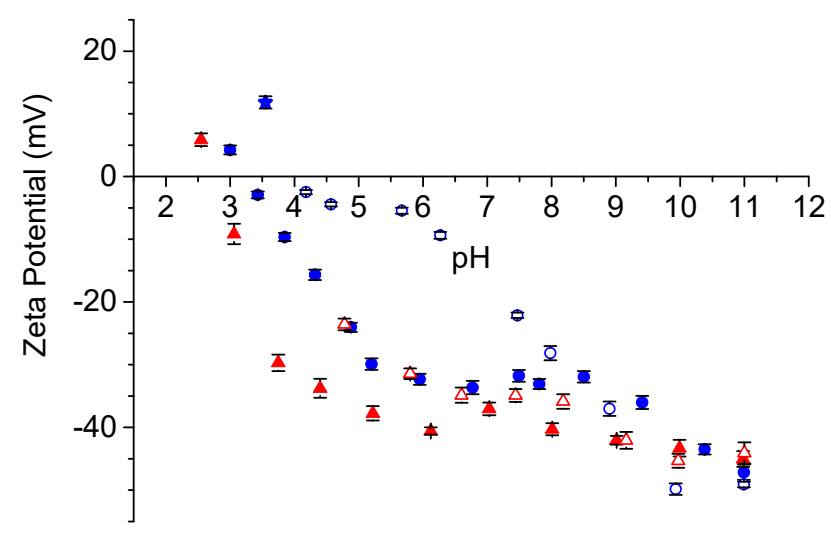




\section{Graphical Abstract}

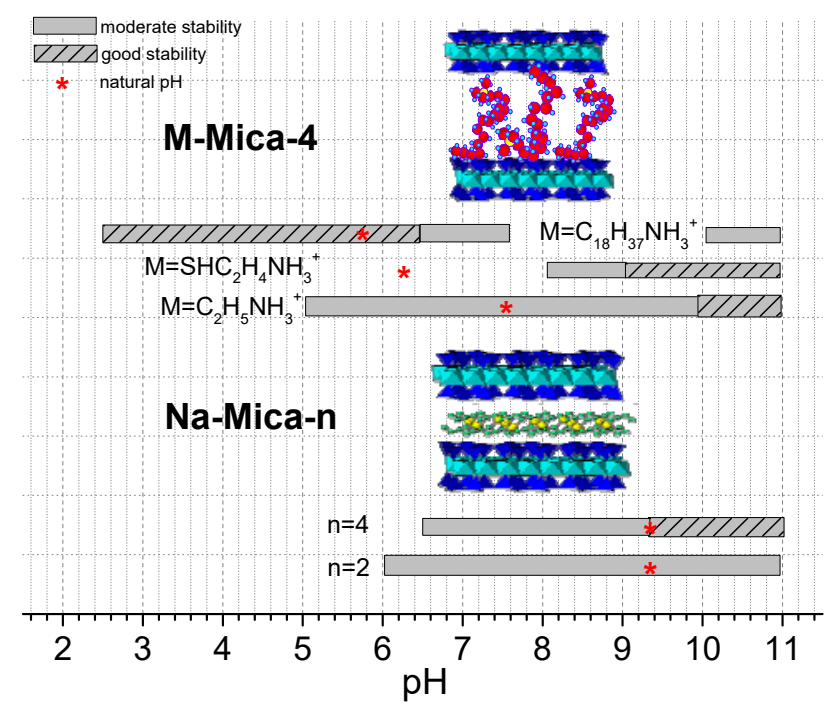




\section{References}

[1] M. Gregorkiewitz, J.A. Rausellcolom, Characterization and properties of a new synthetic silicate with highly charged mica-type layers, Am. Miner., 72 (1987) 515-527. [2] M. Park, D.H. Lee, C.L. Choi, S.S. Kim, K.S. Kim, J. Choi, Pure Na-4-mica: Synthesis and characterization, Chem. Mat., 14 (2002) 2582-2589.

[3] S. Komarneni, R. Ravella, M. Park, Swelling mica-type clays: synthesis by $\mathrm{NaCl}$ melt method, NMR characterization and cation exchange selectivity, J. Mater. Chem., 15 (2005) 4241-4245.

[4] M.D. Alba, M.A. Castro, M. Naranjo, E. Pavon, Hydrothermal reactivity of Na-nmicas $(\mathrm{n}=2,3,4)$, Chem. Mat., 18 (2006) 2867-2872.

[5] R. Ravella, S. Komarneni, C.E. Martinez, Highly charged swelling mica-type clays for selective Cu exchange, Environ. Sci. Technol., 42 (2008) 113-118.

[6] M.J. Garcia-Jimenez, A. Cota, F.J. Osuna, E. Pavon, M.D. Alba, Influence of temperature and time on the Eu3 + reaction with synthetic Na-Mica-n ( $\mathrm{n}=2$ and 4), Chem. Eng. J., 284 (2016) 1174-1183.

[7] F.J. Osuna, A. Cota, E. Pavon, M.C. Pazos, M.D. Alba, Cs+ immobilization by designed micaceous adsorbent under subcritical conditions, Appl. Clay Sci., 143 (2017) 293-299.

[8] M.D. Alba, M.A. Castro, M.M. Orta, E. Pavon, M.C. Pazos, J.S.V. Rios, Formation of Organo-Highly Charged Mica, Langmuir, 27 (2011) 9711-9718.

[9] M.C. Pazos, M.A. Castro, A. Cota, F.J. Osuna, E. Pavon, M.D. Alba, New insights into surface-functionalized swelling high charged micas: Their adsorption performance for non-ionic organic pollutants, J. Ind. Eng. Chem., 52 (2017) 179-186. 
[10] F. Bergaya, G. Lagaly, Intercalation processes of layered minerals, in: M.F. Brigatti, A. Mottana (Eds.) Layered Mineral Structures and Their Application in Advanced Technologies, Mineralogical Society Great Britain \& Ireland, London, 2011, pp. 259284.

[11] H.P. He, Q. Tao, J.X. Zhu, P. Yuan, W. Shen, S.Q. Yang, Silylation of clay mineral surfaces, Appl. Clay Sci., 71 (2013) 15-20.

[12] L.B. de Paiva, A.R. Morales, F.R.V. Diaz, Organoclays: Properties, preparation and applications, Appl. Clay Sci., 42 (2008) 8-24.

[13] L.Z. Zhu, B.L. Chen, X.Y. Shen, Sorption of phenol, p-nitrophenol, and aniline to dual-cation organobentonites from water, Environ. Sci. Technol., 34 (2000) 468-475.

[14] S.S. Ray, M. Okamoto, Polymer/layered silicate nanocomposites: a review from preparation to processing, Prog. Polym. Sci., 28 (2003) 1539-1641.

[15] N. Güngör, T. Tulun, Studies on the zetha potential of bentonite clay in aqueous solution, Rev. Roumaine de Chimie, 39 (1994) 177-182.

[16] H.H. Murray, Traditional and new applications for kaolin, smectite, and palygorskite: a general overview, Appl. Clay Sci., 17 (2000) 207-221.

[17] E.J.M. Hensen, T.J. Tambach, A. Bliek, B. Smit, Adsorption isotherms of water in Li-, Na-, and K-montmorillonite by molecular simulation, J. Chem. Phys., 115 (2001) $3322-3329$.

[18] M. Fernandez, G. Curutchet, R.M.T. Sanchez, Removal of Humic Acid by OrganoMontmorillonites: Influence of Surfactant Loading and Chain Length of Alkylammonium Cations, Water Air Soil Pollut., 225 (2014) 11.

[19] W. Xie, Z.M. Gao, W.P. Pan, D. Hunter, A. Singh, R. Vaia, Thermal degradation chemistry of alkyl quaternary ammonium montmorillonite, Chem. Mat., 13 (2001) 29792990. 
[20] V. Balek, M. Benes, J. Subrt, J.L. Perez-Rodriguez, P.E. Sanchez-Jimenez, L.A. Perez-Maqueda, J. Pascual-Cosp, Thermal characterization of montmorillonite clays saturated with various cations, J. Therm. Anal. Calorim., 92 (2008) 191-197.

[21] E. Pavon, M.A. Castro, M. Naranjo, M.M. Orta, M.C. Pazos, M.D. Alba, Hydration properties of synthetic high-charge micas saturated with different cations: An experimental approach, Am. Miner., 98 (2013) 394-400.

[22] S. Yariv, The role of charcoal on DTA curves of organo-clay complexes: an overview, Appl. Clay Sci., 24 (2004) 225-236.

[23] J.H. Yang, Y.S. Han, J.H. Choy, H. Tateyama, Intercalation of alkylammonium cations into expandable fluorine mica and its application for the evaluation of heterogeneous charge distribution, J. Mater. Chem., 11 (2001) 1305-1312.

[24] M. Onal, Examination of some commercial sorptive organobentonites, Turk. J. Chem., 31 (2007) 579-588.

[25] M.A. Osman, M. Ploetze, U.W. Suter, Surface treatment of clay minerals - thermal stability, basal-plane spacing and surface coverage, J. Mater. Chem., 13 (2003) 23592366.

[26] D.R. Narine, R.D. Guy, Interactions of some large organic cations with bentonite in dilute aqueous systems, Clay Clay Min., 29 (1981) 205-212.

[27] M.C. Pazos, M.A. Castro, M.M. Orta, E. Pavon, J.S.V. Rios, M.D. Alba, Synthetic High-Charge Organomica: Effect of the Layer Charge and Alkyl Chain Length on the Structure of the Adsorbed Surfactants, Langmuir, 28 (2012) 7325-7332.

[28] S. Ganguly, K. Dana, S. Ghatak, Thermogravimetric study of n-alkylammoniumintercalated montmorillonites of different cation exchange capacity, J. Therm. Anal. Calorim., 100 (2010) 71-78. 
[29] G.W. Brindley, R.W. Hofmann, Orientation and packing of aliphatic chain molecules on montmorillonite, Proceedings of the 9th National Conference,, Pergamon Press, West Lafayette, Indiana,, 1960, pp. 546-556.

[30] W.D. Johns, P.K. Sengupta, Vermiculite-alkyl ammonium complexes, Am. Miner., 52 (1967) 1706-\&.

[31] G. Lagaly, Layer Charge Determination by Alkylammonium Ions, im Chare Charcteristics of 2:1 Clay Minerals, The Chemistry of Clay-Organic Reacions, CMS Workshop 6, The Clay Mineral Society, Boulder, CO, 1994, pp. 1-46.

[32] G. Lagaly, Layer charge heterogeneity in vermiculites, Clay Clay Min., 30 (1982) 215-222.

[33] R. Patakfalvi, I. Dekany, Structural properties of cationic surfactant/pentanol/water systems and their interaction with negatively charged layer silicates, Colloid Surf. APhysicochem. Eng. Asp., 183 (2001) 715-724.

[34] A. Radian, M. Carmeli, D. Zadaka-Amir, S. Nir, E. Wakshal, Y.G. Mishael, Enhanced removal of humic acid from water by micelle-montmorillonite composites: Comparison to granulated activated carbon, Appl. Clay Sci., 54 (2011) 258-263.

[35] M. Fernandez, M.D. Alba, R.M.T. Sanchez, Effects of thermal and mechanical treatments on montmorillonite homoionized with mono- and polyvalent cations: Insight into the surface and structural changes, Colloid Surf. A-Physicochem. Eng. Asp., 423 (2013) 1-10.

[36] X.D. Liu, X.C. Lu, A thermodynamic understanding of clay-swelling inhibition by potassium ions, Angew. Chem.-Int. Edit., 45 (2006) 6300-6303.

[37] P. Mignon, P. Ugliengo, M. Sodupe, E.R. Hernandez, Ab initio molecular dynamics study of the hydration of $\mathrm{Li}+, \mathrm{Na}+$ and $\mathrm{K}+$ in a montmorillonite model. Influence of isomorphic substitution, Phys. Chem. Chem. Phys., 12 (2010) 688-697. 
[38] Swartzen.Sl, E. Matijevic, Surface and colloid chemistry of clays, Chem. Rev., 74 (1974) 385-400.

[39] W.H. Slabaugh, L.S. Carter, Hydrophilic-hydrophobic character of organomontmorillonites, J. Colloid Interface Sci., 27 (1968) 235-\&.

[40] G. Bridley, Clay-organic studies, Clay Minerals, 6 (1965) 91-96.

[41] K. Emmerich, Spontaneous rehydroxylation of a dehydroxylated cis-vacant montmorillonite, Clay Clay Min., 48 (2000) 405-408.

[42] D.A. Laird, Layer charge influences on the hydration of expandable 2 : 1 phyllosilicates, Clay Clay Min., 47 (1999) 630-636.

[43] H. van Olphen, An introduction to clay colloid chemistry, Interscience Publishers, New York, 1963.

[44] I. Sondi, J. Biscan, V. Pravdic, Electrokinetics of pure clay minerals revisited, J. Colloid Interface Sci., 178 (1996) 514-522.

[45] F. Thomas, L.J. Michot, D. Vantelon, E. Montarges, B. Prelot, M. Cruchaudet, J.F. Delon, Layer charge and electrophoretic mobility of smectites, Colloid Surf. APhysicochem. Eng. Asp., 159 (1999) 351-358.

[46] J.D.G. Duran, M.M. Ramos-Tejada, F.J. Arroyo, F. Gonzalez-Caballero, Rheological and electrokinetic properties of sodium montmorillonite suspensions - I. Rheological properties and interparticle energy of interaction, J. Colloid Interface Sci., 229 (2000) 107-117.

[47] B.M. Lombardi, R.M.T. Sanchez, P. Eloy, M. Genet, Interaction of thiabendazole and benzimidazole with montmorillonite, Appl. Clay Sci., 33 (2006) 59-65.

[48] S.A. Hussain, S. Demirci, G. Ozbayoglu, Zeta potential measurements on three clays from Turkey and effects of clays on coal flotation, J. Colloid Interface Sci., 184 (1996) $535-541$. 
[49] B. Rand, E. Pekenc, J.W. Goodwin, R.W. Smith, Investigation into the existence of edge-face coagulated structures in na-montmorillonite suspensions, Journal of the Chemical Society-Faraday Transactions I, 76 (1980) 225-235.

[50] T. Permien, G. Lagaly, The rheological and colloidal properties of bentonite dispersions in the presence of organic-compounds .3. The effect of alcohols on the coagulation of sodium montmorillonite, Colloid Polym. Sci., 272 (1994) 1306-1312.

[51] R. Keren, D.L. Sparks, The role of edge surfaces in flocculation of 2-1 clay-minerals, Soil Sci. Soc. Am. J., 59 (1995) 430-435.

[52] M.D. Alba, A.I. Becerro, M.A. Castro, A.C. Perdigon, J.M. Trillo, Inherent acidity of aqua metal ions in solids: An assay in layered aluminosilicates, J. Phys. Chem. B, 107 (2003) 3996-4001.

[53] M.J. Wilson, A Handbook of Determinative Methods in Clay Mineralogy, Chapman and Hall, New York, 1987.

[54] R.M.T. Sanchez, M.J. Genet, E.M. Gaigneaux, M.D. Afonso, S. Yunes, Benzimidazole adsorption on the external and interlayer surfaces of raw and treated montmorillonite, Appl. Clay Sci., 53 (2011) 366-373.

[55] A. Radian, Y.G. Mishael, Characterizing and designing polycation - Clay nanocomposites as a basis for imazapyr controlled release formulations, Environ. Sci. Technol., 42 (2008) 1511-1516.

[56] P. Praus, M. Turicova, S. Studentova, M. Ritz, Study of cetyltrimethylammonium and cetylpyridinium adsorption on montinorillonite, J. Colloid Interface Sci., 304 (2006) 29-36.

[57] M. Rozic, S. Miljanic, Sorption of HDTMA cations on Croatian natural mordenite tuff, J. Hazard. Mater., 185 (2011) 423-429. 
[58] S. Dultz, J. Bors, Organophilic bentonites as adsorbents for radionuclides II. Chemical and mineralogical properties of HDPy-montmorillonite, Appl. Clay Sci., 16 (2000) 15-29.

[59] G.J. Churchman, Formation of complexes between bentonite and different cationic polyelectrolytes and their use as sorbents for non-ionic and anionic pollutants, Appl. Clay Sci., 21 (2002) 177-189.

[60] D. Zadaka, A. Radian, Y.G. Mishael, Applying zeta potential measurements to characterize the adsorption on montmorillonite of organic cations as monomers, micelles, or polymers, J. Colloid Interface Sci., 352 (2010) 171-177.

[61] G. Lagaly, Characterization of clays by organic-compounds, Clay Minerals, 16 (1981) 1-21. 